WellBeing International

WBI Studies Repository

10-1997

\title{
Weapon Size Versus Body Size as a Predictor of Winning in Fights Between Shore Crabs, Carcinus maenas (L.)
}

\author{
Lynne U. Sneddon \\ University of Glasgow \\ Felicity A. Huntingford \\ University of Glasgow \\ Alan C. Taylor \\ University of Glasgow
}

Follow this and additional works at: https://www.wellbeingintlstudiesrepository.org/acwp_vsm

Part of the Animal Studies Commons, Behavior and Ethology Commons, and the Comparative Psychology Commons

\section{Recommended Citation}

Sneddon, L. U., Huntingford, F. A., \& Taylor, A. C. (1997). Weapon size versus body size as a predictor of winning in fights between shore crabs, Carcinus maenas (L.). Behavioral Ecology and Sociobiology, 41(4), 237-242.

This material is brought to you for free and open access by WellBeing International. It has been accepted for inclusion by an authorized administrator of the WBI Studies Repository. For more information, please contact wbisr-info@wellbeingintl.org.

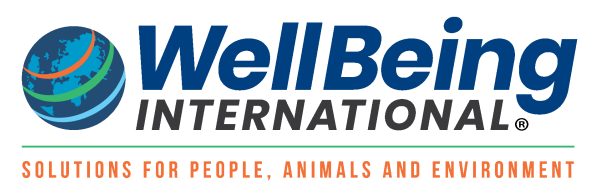




\title{
Weapon size versus body size as a predictor of winning in Fights between shore crabs, Carcinus maenas (L.)
}

\author{
Lynne U. Sneddon, Felicity A. Huntingford, Alan C. Taylor \\ University of Glasgow
}

\section{KEYWORDS}

agonistic behavior, relative size, Shore crab, Carcinus maenas, resource holding potential

\begin{abstract}
Relative body size (carapace width) and weapon size (chela length) were used as indicators of resource holding potential (RHP) in the agonistic behaviour of male shore crabs, Carcinus maenas (L.). Weapon size was found to be a more reliable predictor of the outcome of pairwise fights than body size. Crabs with longer chelae than their opponents were more likely to win fights than crabs with relatively larger bodies. Body size had less influence on the outcome of fights. Relative body and weapon size did not influence initiation of contests but did affect the likelihood of winning; however, this was significant only for weapon size. Winning crabs had heavier claws with greater surface area than losing crabs. There was no relationship between relative size and fight duration. The frequency of cheliped display increased with chela length and winners performed significantly more displays than losers.
\end{abstract}

\section{Introduction}

When resource value and ownership are symmetrical, the probability of an individual winning an agonistic interaction is closely related to its absolute fighting ability or resource holding potential (RHP) relative to that of its opponent (Parker 1974). The RHP of an animal is influenced by a number of interacting factors; for example, morphology (body size in stomatopods, Caldwell and Dingle 1979; weight in spiders, Riechert 1984), physiology (energy reserves in crayfish, Hazlett et al. 1975), and previous agonistic experience (Thorpe 1994). Game theory predictions suggest that during aggressive encounters contestants compare their own RHP with that of opponents before deciding to escalate, and that where contestants are evenly matched, long, intense fights are likely to occur (Maynard Smith 1982; Enquist and Leimar 1983; Archer 1988). This has been demonstrated in animals as diverse as bowl and doily spiders, Frontinella pyramitela (Austad 1983; Suter and Keiley 1984), red deer, Cervus elaphus (Clutton-Brock et al. 1982), the portunid crab, Necora puber (Smith et al. 1994) and the Mozambique mouthbrooder, Oreochromis mossambicus (Turner and Huntingford 1986).

Many of these empirical studies used overall body size as an index of RHP. However, RHP is complex, and may actually depend on something that correlates with body size (e.g. weapon size) and perhaps the ability to inflict injury, rather than on body size per se (Maynard Smith and Brown 1986). Weapons such as horns in ungulates, claws and mandibles in arthropods, and spurs in birds have been shown to be 
important in agonistic behaviour (review in Andersson 1994). Removal of antlers in male reindeer, Rangifer tarandus, and red deer reduces their fighting ability and dominance status, although age, body size and condition also play a role (e.g. Espmark 1964; Lincoln 1972; Prowse et al. 1980; Clutton-Brock et al. 1982). In this study we try to disentangle the relative effects of body size and weapon size on the outcome of agonistic behaviour in shore crabs, Carcinus maenas (L.) by staging contests between pairs of males.

Crustaceans are ideal subjects for laboratory studies of aggression since they fight readily in laboratory conditions, have formidable weapons (the chelae or claws), and are relatively easy to manipulate and measure. The general nature of agonistic behaviour in crustaceans involves an exchange of agonistic signals where the body is raised high above the substratum by the ambulatory legs and the weapons are presented to the opponent (Dingle 1983). Agonistic interactions may be resolved at this point or may escalate to fighting behaviour. In studies of stomatpods, Gonodactylus viridis (Caldwell and Dingle 1979), crayfish, Cherax cuspidatus (Pavey and Fielder 1996) and portunid crabs (e.g. Thorpe et al. 1995) larger individuals were found to have a high probability of winning against a smaller opponent. These investigations interpreted body size (carapace width or length) as the empirical determinant of RHP.

Fig. 1 The relationship between chela length and carapace width showing the amount of variation in chela size for a given carapace width. Data points refer to crabs used in this study $\left(y=-2.9272+0.6757 x, r^{2}=0.38 ; n=94\right)$

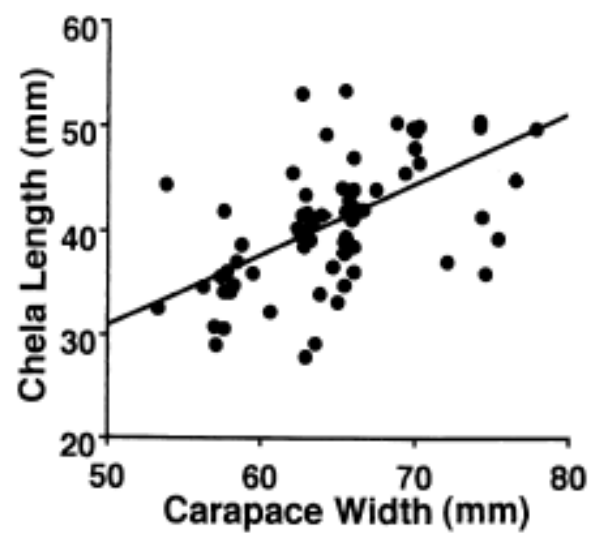

After maturation, the chelae of decapod crustaceans grow relatively to the carapace size and hence a linear relationship exists between these two variables, with the chelae length increasing with carapace width (Hartnoll 1982). It is therefore possible that the effect of size on fight outcome is actually predicted by chela size rather than body size. In addition, due to inherited individual differences and loss of chelipeds through damage or escape from predators, for any given carapace width there can be a range of chela sizes (Fig. 1 shows data for the crabs used in this study). Such differences in weapon size may be particularly important in settling fights between individuals with evenly matched body size. Therefore we examined the relative effects of weapon size and body size on the content, duration and outcome of pairwise fights between male shore crabs.

\section{Materials and methods}

Maintenance of study animals

We obtained 64 male Carcinus maenas (carapace width range $55-80 \mathrm{~mm}$ ) from the University Marine Biological Station, Millport, Isle of Cumbrae where they had been freshly caught by creeling from the 
Clyde Sea area. On their arrival we transferred the crabs to individual holding tanks (18 x $21 \times 23 \mathrm{~cm})$, supplied with circulating seawater (salinity $32-34 \%$ ) maintained at $12 \pm 2{ }^{\circ} \mathrm{C}$ and on a $12: 12 \mathrm{~h}$ light-dark cycle, with experiments being carried out in the light period. We kept the crabs in these isolated conditions for at least 7 days prior to any behavioural observations and during this time they were provided with whitebait to excess once every 5 days. C. maenas can withstand food deprivation for 3 months so this regime kept the crabs healthy but motivated to fight over food (Wallace 1973).

Assessing size

We used crabs in behavioural observations only if they were in pristine condition, i.e. the exoskeleton was hard, there was no excessive epifaunal growth and there were no missing or recently regenerated limbs. A few days prior to each fight we measured the carapace width of the crabs to the nearest $0.1 \mathrm{~mm}$ between the fourth and fifth lateral spines, using vernier callipers. From these measurements we calculated the body size ratio of the interactants by dividing the carapace width of the smaller opponent by that of the larger. This was repeated for the major chela length (the total propodus length). After completion of experiments we held the crabs for a further two weeks to make sure they were not in proecdysis, which none were.

\section{Experimental protocol}

A total of 56 crabs were used in this study of which 36 had to be used more than once due to the constraints of obtaining animals and the limited space available in which to house them. Crabs fought no more than twice, and in the second interaction fights were staged between a pair of winners or a pair of losers from previous fights. At least 7 days were allowed between fights and crabs never fought against opponents they had previously encountered. Therefore each pairing was treated as an independent event.

We staged 46 fights by placing two crabs in a glass observation tank (48 $\times 43 \times 34 \mathrm{~cm})$, with a gravel substratum, filled with aerated seawater which was screened from visual disturbance. Crabs were separated by a vertically sliding opaque partition to allow them a settling time of 15 min in continued isolation. To reduce the possibility of chemical communication, the air and water pumps were switched off to minimise mixing during the settling period. The tank was illuminated from above at a light intensity of 1.82-2.66 $\mu \mathrm{E}^{\mathrm{m}-2} \mathrm{~s}^{-1}$ at the top and 0.89-1.40 $\mu \mathrm{E} \mathrm{m}^{-2} \mathrm{~s}^{-1}$ at the bottom of the tank. We made observations through a small opening in the screen. After the initial settling period and when both crabs were stationary, the partition was raised from outside the screen by a pulley, and $10 \mathrm{ml}$ of food extract (whitebait homogenised in seawater) was added, via a burette, into the centre of the arena at the start of the experiment. We recorded the actions of both crabs using a laptop computer as an event recorder. These behavioural data are presented elsewhere (Sneddon et al., in press). The frequency of cheliped display was recorded and analysed for this study. The end of a contest was judged to have occurred when the two crabs separated and did not interact for 5 min.

The crab that first moved to its opponent and engaged in physical contact was defined as the initiator. The winner was the crab that successfully climbed on top of its opponent or elicited repeated retreats from the other crab, (the loser). The duration of the first bout of fights was measured by analysis of the event recorder data. The duration of the first bout was the time from initiation to when the two crabs disengaged for the first time or one crab retreated from the other. The overall duration was the time from initiation to when no further aggressive acts were performed by either crab.

Fourteen pairs of crabs, taken from a separate group of crabs with each pair being matched for chela length, were humanely killed by immersion in liquid nitrogen after fighting (under the same experimental 
conditions as described before) and the major chela taken off by careful dissection using a scalpel. The sample size of 14 was chosen for ethical reasons. The area of the outer surface of the major chela of each crab was calculated by video image analysis. After removal from the crab, each chela was held in a standardised orientation at a specified distance from a video camera (Sony CCD-FX700E) on a set magnification. A scale bar was also filmed so that the videos could be calibrated accurately. The video tapes were subsequently digitised and analysed using the public domain NIH Image program (written by Wayne Rasband at the U.S. National Institutes of Health) on a Power Macintosh 7500/100AV to give estimates of chela surface area. Each measurement was performed twice and surface area measures were shown to be highly repeatable (intraclass correlation coefficient $(\operatorname{Zar} 1984), r_{1}=0.9973, F_{14,1}=$ 742.85, $P<0.00001$.).

The major chela used in the surface area analyses were placed in a preweighed vial and freeze dried (Edwards Modulyo) then weighed accurately.

\section{Statistical analysis}

A chi-square test was performed on the number of absolute smaller or larger crabs (chela and body size) initiating fights and winning fights. A binary logistic regression was used to determine the importance of the proportional difference in chela length (relative chela length) and carapace width (relative carapace width) in predicting the outcome of fights. The event probability (likelihood of larger or smaller crab winning) was also calculated.

The surface area and weight of the major chela of winners and losers were compared using a paired $t$ test.

To determine if fight duration or length of first bout was related to relative size of body and weapons of fighting pairs, a regression analysis was carried out.

The frequency of cheliped display was calculated for winners and losers and a paired $t$-test performed on the data to compare the behaviour of winners and losers. Regression analysis of frequency of cheliped display against chela size was carried out and ANOVA used to compare the regression lines of winners and losers. Two-tailed tests of significance were used throughout and the $\mathrm{P}$ values were adjusted for multiple testing.

\section{Results}

The relations between absolute size difference in carapace and chela size and the probability of initiation and winning are shown in Table 1 . Size was not related to initiation but there was a significant relationship between chela length and the likelihood of winning $\left(X^{2}=4.08, P<0.01, n=46\right)$. A similar but not significant effect was found for carapace width $\left(X^{2}=1.6, P>0.05, n=46\right)$. In both cases there is a range of size differences where the winner may be smaller (chela difference 0-6 mm; carapace difference 0-9 $\mathrm{mm}$ ). The surface area of the major chela of winning crabs (mean $1.717 \mathrm{~cm}^{2}$, SE 0.123 ) was significantly higher than that of losers (mean $1.485 \mathrm{~cm}^{2}$, SE 0.104, $t=3.38, P=0.0049, n=14$ ) and the dry weight of the chela was also found to be significantly higher in winners (mean $3.728 \mathrm{~g}$, SE 0.481) than in losers (mean $3.022 \mathrm{~g}$, SE 0.403, $t=8.44, P<0.00001, n=14$ ).

Figure 2 shows the results of a logistic regression showing the importance of relative carapace width and chela length (Fig. 2). When the probability (solid line, Fig. 2) of the larger crab winning is equal to 0.5 there is an equal chance of either opponent winning; i.e. the two crabs are evenly matched. As the line moves towards 1.0, the probability of the larger opponent winning increases i.e. the shorter the section of the $x$ axis for which the probability is intermediate, the stronger the determinate of fight outcome. Relative 
carapace width does not reliably predict the outcome of fights $(z=0.50, P=0.618$, odds ratio $=9.35)$ and the slope of the line is not significantly different from zero $(G=0.259, d f=1, P=0.611$. In contrast, relative chela length is a reliable predictor of the larger crab winning $(z=2.227, P=0.027$, odds ratio $=$ $\left.4.67^{\prime} 10^{-6}\right)$, with the slope of the line being significantly different from zero ( $G=6.853, d f=1, P=0.009$ ). Therefore chela length is a more reliable predictor of the winner of pairwise fights between shore crabs than carapace width.

Table 1 The number of larger and smaller crabs initiating and winning fights in staged contests with percentage shown in brackets. Results for carapace width and chela length ratio are shown separately. The significance of the v2 test is shown by the resulting $P$ value ( $n=46$ with 4 losing crabs having both larger bodies and chelae)

\begin{tabular}{|c|c|c|c|c|c|c|}
\hline & \multicolumn{3}{|c|}{ Carapace width } & \multicolumn{3}{|c|}{ Chela Length } \\
\hline & Smaller & Larger & $P$ & Smaller & Larger & $P$ \\
\hline Initiate & $21(45 \%)$ & $26(55 \%)$ & n.s & $19(41 \%)$ & $27(59 \%)$ & n.s \\
\hline Win & 15 (32\%) & 31 (68\%) & n.s & $10(22 \%)$ & $36(78 \%)$ & 0.01 \\
\hline
\end{tabular}

Overall fight duration is not related to either carapace width or chela length differential $\left(F_{44}=0.16, P=\right.$ $0.694 ; F_{44}=0.02, P=0.881$ respectively), and thus duration cannot be predicted by the relative size of opponents. Similarly the length of the first bout of these fights is unrelated to either relative carapace width $\left(F_{44}=0.24, P=0.624\right)$ or chela length $\left(F_{44}=0.07, P=0.792\right)$.

The frequency of cheliped display per minute was calculated for winners (mean 1.51, SE 0.09, $n=32$ ) and losers (mean 0.963, SE 0.105, $n=32$ ). A regression analysis showed that, using data for both winners and losers, cheliped display frequency increased significantly with chela size (regression equation $y=0.11+0.0331 x, r^{2}=0.188 ; F_{62}=6.94, P=0.013$ ). Figure 3 shows the frequency of cheliped display for winners and losers separately. When comparing the slope of the two lines using ANOVA, it was found that they were not significantly different $\left(F_{30}=0.04, P=0.85\right)$ but winners performed significantly more cheliped displays than losing crabs $\left(F_{30}=9.64, P<0.01\right)$ and a paired $t$-test confirmed this $(t=5.28, \mathrm{P}<0.01, n=32)$.

\section{Discussion}

Relative chela size appears to be more important than relative body size in influencing the outcome of agonistic contests between male $C$. maenas. This result indicates that weapon size may be a more reliable indicator of RHP than body size in these crabs. Relative size, for both carapace width and chela length, does not influence the duration of bouts and hence does not agree with the prediction of game theory that as opponents become more evenly matched the duration of fights increases (Maynard Smith 1982). Other studies have also failed to find a relationship between fight duration and relative size, e.g. in dungflies, Scatophaga stercoraria (Sigurjonsdottir and Parker 1981). Fight duration is highly variable and unpredictable in the contests of $C$. maenas. In contrast, in fights between male Necora puber, the duration of interactions decreased as crabs became more disparate in size (Smith et al. 1994). The absence of a relationship between either index of relative size and duration of first bout suggests that the lack of a relationship where overall duration is concerned, is not due to the crabs being concerned in an experimental tank where they are forced to stay in close proximity to one another. From field observations, shore crab fights involve one bout and no re-engagement of an opponent occurs since the loser can retreat well away (L.U. Sneddon, personal observations).

The chelipeds comprise a substantial proportion of total body weight (20\% in C. maenas, Lee and Seed 1992) and chela size is critically important in mating success, foraging, mate acquisition and defence, and to reduce inter- and intraspecific attack (review in Juanes and Smith 1995). In the shore crab C. maenas, 
it has been shown that paired, mating males have larger chelae compared to the average of the entire male population of that site (Lee and Seed 1992); however, no data on body size were collected. In addition, it is known that limb damage has a negative effect on male pairing success and chela loss impaired the ability of male $C$. maenas to compete for and also to defend a receptive female (Sekkelsten 1988; Abello et al. 1994). When a model of the shed exoskeleton of $C$. maenas was presented to shore crabs, the results suggested that the size of the chelae was more important in eliciting an aggressive reaction than body size (Lee and Seed 1992). This study of live crabs confirms this hypothesis, chela size is more important in influencing the outcome of flights than body size and these results are more conclusive since Lee and Seed did not investigate actual outcomes of fights. This relationship has not been demonstrated in other portunids, although chela size has not previously been considered as an indicator of RHP (Jachowski 1974; Smith et al. 1994; Thorpe et al. 1995).

Fig. 2 These graphs illustrate the results of a logistic regression performed on the proportional size difference in chela length (above) and carapace width (below) and on whether the winner was larger or smaller. The solid lines are the probabilities of a smaller or larger crab winning (points at 0.0 and 1.0 are smaller and larger winners respectively)

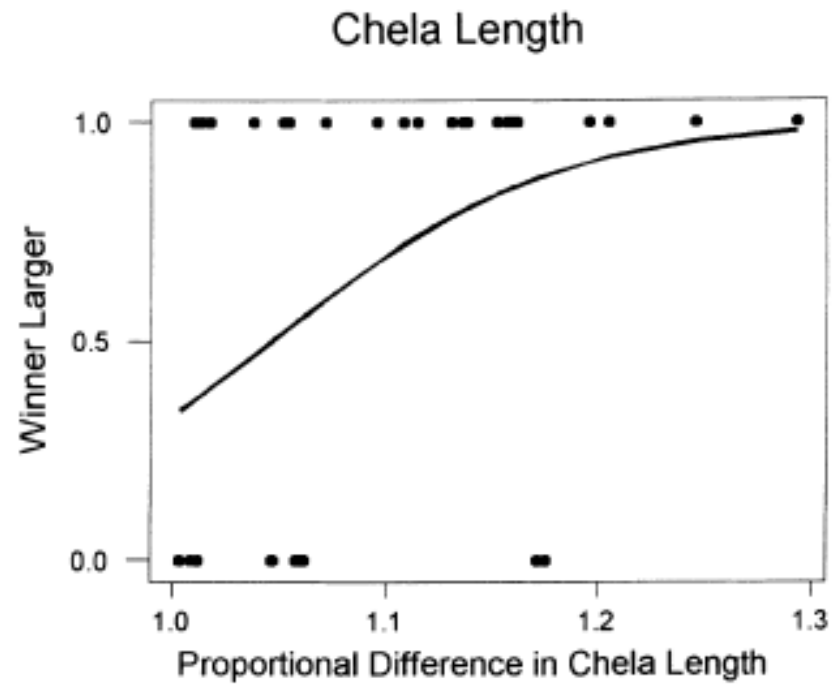

Carapace Width

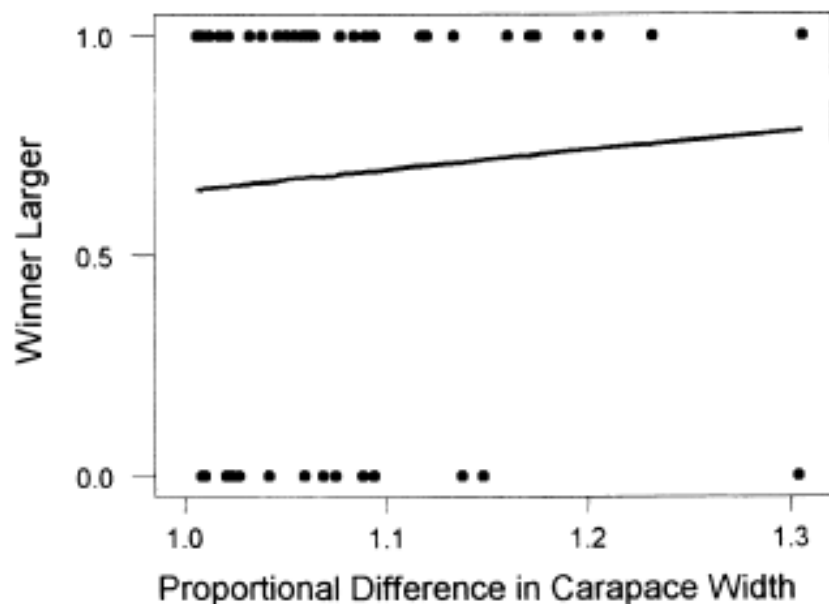


Fig. 3 Mean cheliped display with chela length is shown for winners (solid circles, $y=0.78+0.017 x, r^{2}=0.093 ; n=32$, solid line) and losers (empty circles, $y=0.13+0.022 x, r^{2}=0.068 ; n=32$, dashed line) of pairwise fights

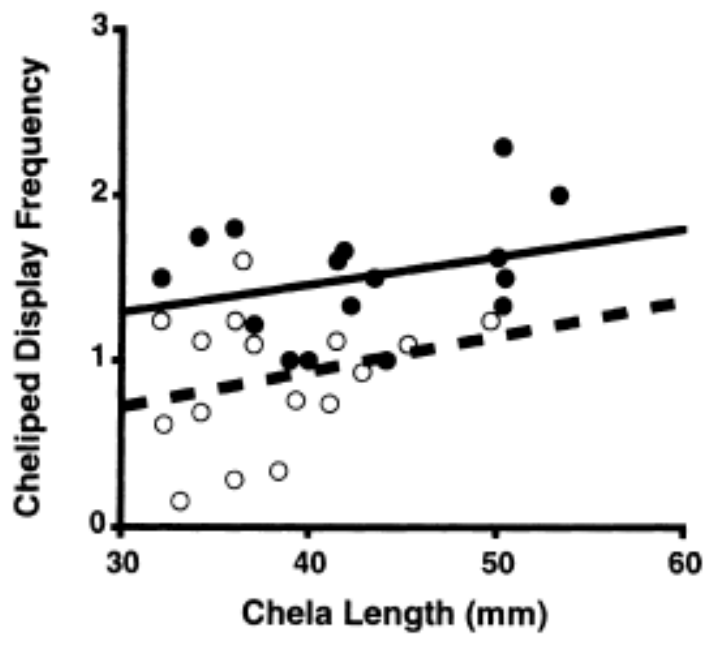

Since most agonistic behaviours employ the chelipeds, which are used in displays as well as weapons, it may not be surprising that these structures greatly influence individual RHP. We propose that crabs, when facing up to each other, may be able to assess the size or reach of opponents' chelipeds, which are presented to them. It has been shown in C. maenas that a relationship exists between increasing height of the chelae and the exertion of greater force (Lee 1993). Gabbanini et al. (1995) have shown that chela size influences dominance in female freshwater crabs, Potamon fluviatile, and this might be important in intraspecific agonistic encounters of $C$. maenas where grasping is prevalent.

Several studies have shown the importance of weapon size in male agonistic behaviour (e.g. the horned beetle, Bolithotherus cornutus, Brown and Bartalon 1986; red deer, Clutton-Brock et al. 1982; pseudoscorpions, Dinocheirus arizonensis, Zeh 1987a,b). It has been suggested that males with large weapons may be in "good" condition and that this trait may be an indicator of male phenotypic and genotypic quality (Kodric-Brown and Brown 1984; Andersson 1986). This may be important in the mating success of individual male $C$. maenas since studies have shown larger-clawed crabs are more successful in obtaining mates (Lee and Seed 1992) and perhaps individuals with larger claws could prove more attractive to females if weapon size is indeed an indicator of male quality.

Winners perform significantly more cheliped displays than losers. This may indicate a difference in aggressiveness, with crabs with larger claws being more motivated to fight and so displaying them more. Alternatively, if claw size is the decisive factor, then the increased presentation of the claws by winners is a strategy they adopt to establish their dominance over an opponent. Another explanation may be that crabs in "good" condition may be able to grow bigger claws and that they are also more active and are victorious over smaller-clawed crabs. The results of the present study support this hypothesis since crabs with larger surface area and heavier chelae won most fights.

It could be argued that, since the crabs were motivated by moderate starvation, this would influence the outcome of these fights. Presumably body size would determine the relative effect of starvation in large and small crabs, such that crabs with bigger bodies would be rendered hungrier by a given period of starvation than crabs with smaller bodies. This would strengthen a body size effect at the expense of a 
cheliped effect; however, this study has found the opposite. Therefore the effects of starvation on different sized crabs cannot be influencing the data.

In other species of Crustacea (Hyatt 1983) and in other taxa (Archer 1988), relative size of combatants influences the duration and outcome of agonistic interactions between them. Contests were usually won by the larger crab while smaller crabs were successful only when the size difference was relatively small. Size is very likely to be related to strength and age in the decapods and thus to reflect RHP (Hartnoll 1982). This effect of size, both of the body and the chela (the more important factor), as a measure of relative RHP and as a predictor of the outcome in the fights of $C$. maenas agrees with game theory predictions (Parker 1974; Maynard Smith and Parker 1976) and is found in many other species such as the crayfish, Orconectes rusticus (Rubenstein and Hazlett 1974), Cherax cuspidatus (Pavey and Fielder 1996), the fiddler crabs, Uca spp. (Hyatt and Salmon 1978), snapping shrimps, Alpheus heterochaelis Say (Schein 1975) and other portunid crabs (e.g. Jachowski 1974; Huntingford et al. 1995). Since the difference in size between two opponents appears to influence winning but not initiation, this would suggest that assessment may be occurring during rather than prior to the interaction (Enquist and Leimar 1983).

This study has shown that weapon size is a more reliable predictor of the outcome of these fights than carapace size and hence is a better indicator of RHP. The majority of other studies have used overall body size as a measure of RHP however weapon size may explain why, when there is little distinction in body size, the smaller bodied opponent wins. In stomatopod species, those species with heavier raptorial appendages are more aggressive (Dingle 1983) and this dissimilarity in weapon size may explain why smaller opponents won, when body length was less than 30\% larger (Caldwell and Dingle 1979). Cheliped display frequency was higher for winners than in losers which may indicate that this behavioural trait, together with chela length, might also affect the outcome of fights.

\section{Acknowledgements}

This work was carried out by L.U.S. whilst in receipt of a NERC studentship. We are grateful to Dr. James Currall for help with the statistical analysis of the data, and to Dr. J.P. Swaddle for his assistance with the surface area measurements.

\section{References}

Abello P, Warman CG, Reid DG, Naylor E (1994) Chela loss in the shore crab Carcinus maenas and its effect on mating success. Mar Biol 121:247-252

Andersson MB (1986) Evolution of condition-dependent sex ornaments and mating preferences: sexual selection based on viability differences. Evolution 40:804-816

Andersson MB (1994) Sexual selection. Princeton University Press, Princeton

Archer J (1988) The behavioural biology of aggression. Cambridge University Press, Cambridge

Austad SN (1983) A game theoretical interpretation of male combat in the bowl and doily spider (Frontinella pyramitela). Anim Behav 31:59-73

Brown L, Bartalon J (1986) Behavioural correlates of male morphology in a horned beetle. Am Nat 127:565-570

Caldwell RL, Dingle J (1979) The influence of size on agonistic encounters in the mantis shrimp, Gonodactylus viridus. Behav 69:255-264 
Clutton-Brock TH, Guiness FE, Albon SD (1982) Red deer: behaviour and ecology of two sexes. Edinburgh University Press, Edinburgh

Dingle H (1983) Strategies of agonistic behaviour in Crustacea. In: Rebach S, Dunham DW (eds) Studies in adaptation: the behaviour of higher Crustacea. Wiley, New York, pp 85-111

Enquist M, Leimar O (1983) Evolution of fighting behaviour: Decision rule and assessment of relative strength. J Theor Biol 102:387-341

Espmark Y (1964) Studies in dominance -- subordination relationship in a group of semi domestic reindeer. Anim Behav 12:420-426

Gabbanini F, Gherardi F, Vannini M (1995) Force and dominance in the agonistic behaviour of the freshwater crab Potamon fluviatile. Aggr Behav 21:451-462

Hartnoll RG (1982) Growth. In: Abele LG (ed) The biology of the Crustacea, vol 2. Embryology, morphology, and genetics. Academic Press, London, pp 111-196

Hazlett BA, Rubenstein DI, Rittschof D (1975) Starvation, energy reserves, and aggression in the crayfish Orconectes virilis. Crustaceana 28:11-16

Huntingford FA, Taylor AC, Smith IP, Thorpe KE (1995) Behavioural and physiological studies of swimming crabs. J Exp Mar Biol Ecol 193:21-39

Hyatt GW (1983) Qualitative and quantitative dimensions of crustacean aggression. In: Rebach S, Dunham DW (eds) Studies in adaptation: the behaviour of the higher Crustacea. Wiley, New York, pp 113-139

Hyatt GW, Salmon M (1978) Combat in the fiddler crabs Uca pugilator and Uca pugnax: a quantitative analysis. Behaviour 65:182-211

Jachowski RL (1974) Agonistic behaviour of the blue crab, Callinectes sapidus Rathbun. Behaviour $50: 232-253$

Juanes F, Smith LD (1995) The ecological consequences of limb damage and loss in decapod crustaceans: a review and prospectus. J Exp Mar Biol Ecol 193:197-223

Kodric-Brown A, Brown JH (1984) Truth in advertising: the kinds of traits favoured by sexual selection. Am Nat 124:305-322

Lee SY (1993) Chela height is an acceptable indicator of chela strength in Carcinus maenas (L.). Crustaceana 65:115-116

Lee SY, Seed R (1992) Ecological implications of cheliped size in crabs: some data from Carcinus maenas and Liocarcinus holsatus. Mar Ecol Prog Ser 84:151-160

Lincoln GA (1972) The role of antlers in the behaviour of red deer. J Exp Zool 182:233-250

Maynard Smith J (1982) Evolution and the theory of games. Cambridge University Press, Cambridge

Maynard Smith J, Brown RLW (1986) Competition and body size. Theor Popul Biol 50:166-171

Maynard Smith J, Parker GA (1976) The logic of asymmetric contests. Anim Behav 24:159-175 
Parker GA (1974) Assessment strategy and the evolution of fighting behaviour. J Theor Biol 47:223-243

Pavey CR, Fielder DR (1996) The influence of size differential on agonistic behaviour in the freshwater crayish, Cherax cuspidatus. J Zool Lond 238:445-457

Prowse DL, Trilling JS, Luich JR (1980) Effects of antler removal on mating behaviour of reindeer. In: Reimers E, Gaare E, Skjenneberg S (eds) Proceedings of the second international reindeer/caribou Symposium. Direktoratet for Vilt og Ferskvannsfisk, Trondheim, pp 528-536

Riechert SE (1984) Games spiders play. III. Cues underlying context-associated changes in agonistic behaviour. Anim Behav 32:1-15

Rubenstein DI, Hazlett BA (1974) Examination of the agonistic behaviour of the crayfish, Orconectes virilis by character analysis. Behaviour 50:193-216

Schein H (1975) Aspects of the aggressive and sexual behaviour of Alpheus heterochaelis Say. Mar Behav Physiol 3:83-96

Sekkelsten GI (1988) Effect of handicap on mating success in male shore crabs Carcinus maenas. Oikos 51:131-134

Sigurjonsdottir H, Parker GA (1981) Dungfly struggles: evidence for assessment strategy. Behav Ecol Sociobiol 8:219-230

Smith IP, Huntingford FA, Atkinson RJA, Taylor AC (1994) Strategic decisions during agonistic behaviour in the velvet swimming crab, Necora puber (L). Anim Behav 47:885-894

Sneddon LU, Huntingford FA, Taylor AC (in press) The influence of resource value on the agonistic behaviour of the shore crab, Carcinus maenas (L.). Mar Freshwater Behav Physiol

Suter RB, Keiley M (1984) Agonistic interactions between male Frontinella pyramitela. Behav Ecol Sociobiol 15:1-7

Thorpe KE (1994) Behavioural and physiological studies of fighting in the velvet swimming crab, Necora puber (L.). PhD thesis, University of Glasgow

Thorpe KE, Huntingford FA, Taylor AC (1995) Relative size and agonistic behaviour in the female velvet swimming crab, Necora puber (L.). Behav Proc 32:235-246

Turner GF, Huntingford FA (1986) A problem for game theory analysis: assessment in male mouthbrooder contests. Anim Behav 34:61-70

Wallace JC (1973) Feeding, starvation and metabolic rate in the shore crab, Carcinus maenas. Mar Biol 20:277-281

Zar JH (1984) Biostatistical analysis. Prentice Hall, New Jersey

Zeh DW (1987a) Aggression, density, and sexual dimorphism in chernetid pseudoscorpions. Evolution 41:1072-1087

Zeh DW (1987b) Life history consequences of sexual dimorphism in a chernetid pseudoscorpion. Ecology 68:1495-1501 